\title{
Choline supplementation prevents diet induced gut mucosa lipid accumulation in post-smolt Atlantic salmon (Salmo salar L.)
}

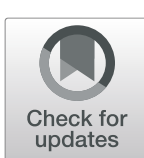

\author{
Anne Kristine G. Hansen ${ }^{1 *}$ (D), Trond M. Kortner ${ }^{2}$, Aleksei Krasnov ${ }^{3}$ Ingemar Björkhem ${ }^{4}$, Michael Penn ${ }^{2,5}$ \\ and Åshild Krogdahl ${ }^{2}$
}

\begin{abstract}
Background: Various intestinal morphological alterations have been reported in cultured fish fed diets with high contents of plant ingredients. Since 2000, salmon farmers have reported symptoms indicating an intestinal problem, which we suggest calling lipid malabsorption syndrome (LMS), characterized by pale and foamy appearance of the enterocytes of the pyloric caeca, the result of lipid accumulation. The objective of the present study was to investigate if insufficient dietary choline may be a key component in development of the LMS.

Results: The results showed that Atlantic salmon (Salmo salar), average weight $362 \mathrm{~g}$, fed a plant based diet for 79 days developed signs of LMS. In fish fed a similar diet supplemented with $0.4 \%$ choline chloride no signs of LMS were seen. The relative weight of the pyloric caeca was $40 \%$ lower, reflecting $65 \%$ less triacylglycerol content and histologically normal gut mucosa. Choline supplementation further increased specific fish growth by $18 \%$. The concomitant alterations in intestinal gene expression related to phosphatidylcholine synthesis (chk and pcyt1a), cholesterol transport (abcg5 and npc1/1), lipid metabolism and transport (mgat2a and fabp2) and lipoprotein formation (apoA1 and apoAM) confirmed the importance of choline in lipid turnover in the intestine and its ability to prevent LMS. Another important observation was the apparent correlation between plin2 expression and degree of enterocyte hyper-vacuolation observed in the current study, which suggests that plin2 may serve as a marker for intestinal lipid accumulation and steatosis in fish. Future research should be conducted to strengthen the knowledge of choline's critical role in lipid transport, phospholipid synthesis and lipoprotein secretion to improve formulations of plant based diets for larger fish and to prevent LMS.
\end{abstract}

Conclusions: Choline prevents excessive lipid accumulation in the proximal intestine and is essential for Atlantic salmon in seawater.

Keywords: Choline, Lipid accumulation, Lipid transport, LMS, Lipid malabsorption, Gut health, Fish feed, Plant ingredients

\section{Background}

The main driver for replacement of marine raw materials with alternative plant ingredients in fish feed is the ambition to maintain growth of the aquaculture industry and to secure flexibility regarding raw materials in feed production. However, in parallel with the decrease in fishmeal and increase in plant meals in fish feed, the prevalence of various intestinal disturbances has increased. Therefore, it

\footnotetext{
* Correspondence: annha@biomar.com

'Biomar AS, Havnegata 9, 7010 Trondheim, Norway

Full list of author information is available at the end of the article
}

is likely that some of the observed intestinal challenges may be due to deficient supply of nutrients, which are present at lower levels in plant ingredients than in fishmeal, but not corrected for due to lack of information on their essentiality and/or required level. The requirements for many nutrients have been defined for many species but all nutrient requirements are far from defined [1].

The present work addresses symptoms of a wellknown intestinal disorder for which we suggest the term lipid malabsorption syndrome (LMS) and which since 2000 have been reported by salmon farmers to affect

(c) The Author(s). 2020 Open Access This article is distributed under the terms of the Creative Commons Attribution 4.0 International License (http://creativecommons.org/licenses/by/4.0/), which permits unrestricted use, distribution, and 
young as well as more mature fish [2-4]. The typical sign is increased lipid accumulation in the enterocytes giving the pyloric caeca a pale and foamy appearance on the macroscopic level. Similar signs have been reported also in other fish species fed diets high in plant meal [5-8] or high in plant oil [7, 9-11]. The apparent disturbance in lipid transport is also observed on the molecular level. Plant based diets may influence the expression of genes involved in lipid metabolism in a manner reflecting reduced lipid export from the enterocytes [8, 12-20]. However, the mechanisms underlying the excessive lipid accumulation are not yet fully clarified. Some studies seem to indicate that phospholipid synthesis, and in particular phosphatidylcholine, might be the bottleneck in lipid export from the enterocytes in fish showing such lipid accumulation [9, 10, 21-27]. Phosphatidylcholine, however, is not established as an essential nutrient for Atlantic salmon nor for any other fish species (NRC, 2011). For choline, on the other hand, of which about $95 \%$ is found in phosphatidylcholine [28, 29], a requirement is established for several fish [1]. Due to insufficient information, the question of whether choline is essential, and if so, the required amount, cannot currently be determined for Atlantic salmon.

In animals, including fish, choline is necessary for synthesis of phosphatidylcholine for use in lipid digestion and absorption, as a component in lipoproteins for lipid transport, in production of the neurotransmitter acetylcholine, and as a methyl donor in a wide range of methylation processes. Poor growth and low feed efficiency, fatty liver, high mortality, and anorexia are all reported effects of choline deficiency in the species for which we have documentation [1,30-32]. Lipid accumulation in the intestinal mucosa is, however, not a common endpoint in studies of choline deficiency and requirement and has only been observed in an early study of Japanese eel (Anguilla japonica) as "white-grey colored intestines" [33]. This gut observation appears similar to that observed in Atlantic salmon with LMS. No studies have been conducted to define whether choline is essential for Atlantic salmon, or how much can be synthesized. Accordingly, a requirement is not established, and the question whether high plant diets might be deficient in phosphatidylcholine or choline, cannot be answered. Rainbow trout have been found to require choline at earlier life stages due to an inability to produce sufficient choline even with a high supply of methyl donors such as betaine and methionine [31]. On the other hand, channel catfish were able to produce sufficient choline, if the supply of methionine was high [1].

The level of fishmeal in today's commercial salmon diets is in general low and decreases throughout the life cycle of the fish. A diet for salmon weighing $500 \mathrm{~g}$ or more typically contains between 5 and 10\% fishmeal.
Fishmeal would be the main contributor for choline in these diets, which means that supply of choline from the other main ingredients would be rather low. For example, the basal diet (LF) used in the present experiment was a commercially representative feed with $10 \%$ fishmeal which revealed a choline level of $944 \mathrm{mg} / \mathrm{kg}$ (Tables 1 and 2). With several recent reports from the salmon industry regarding LMS [4], investigation of the role of choline for LMS is needed. The present work therefore aimed to elucidate whether LMS is a result of insufficient choline supply and also addressed the role of

Table 1 Formulation and chemical composition of the experimental diets

\begin{tabular}{|c|c|c|}
\hline Diets & $\mathrm{LF}^{\mathrm{a}}$ & $\mathrm{LFC}^{\mathrm{b}}$ \\
\hline \multicolumn{3}{|l|}{ Ingredients (g/kg) } \\
\hline Super Prime fra Peru ${ }^{c}$ & 50 & 50 \\
\hline Nordic LT 94 fishmeal $^{d}$ & 50 & 50 \\
\hline Soya $60 \%(S P C)^{\text {e }}$ & 190 & 194 \\
\hline Maize Gluten ${ }^{f}$ & 150 & 150 \\
\hline Pea Protein $50^{\mathrm{g}}$ & 130 & 130 \\
\hline Dehulled Beans ${ }^{h}$ & 140 & 130 \\
\hline Wheat Gluten ${ }^{\mathrm{i}}$ & 19.7 & 19.7 \\
\hline Fish oil (Standard) ${ }^{j}$ & 76.7 & 77.1 \\
\hline Rapeseed oil ${ }^{k}$ & 176 & 177 \\
\hline Amino Acid mix' & 12.4 & 12.4 \\
\hline Mineral mix ${ }^{\prime}$ & 3.0 & 3.0 \\
\hline Monocalcium phosphate ${ }^{\prime}$ & 18.2 & 18.2 \\
\hline Lucantin Pink CWD 10\%' & 0.4 & 0.4 \\
\hline Yttrium $^{\mathrm{m}}$ & 0.5 & 0.5 \\
\hline Choline chloride $70 \%$ & 0 & 4.0 \\
\hline \multicolumn{3}{|c|}{ Analyzed chemical composition ( $/ \mathrm{kg}$ ) } \\
\hline $\mathrm{DM}$ & 975 & 972 \\
\hline Protein & 417 & 418 \\
\hline Fat & 286 & 297 \\
\hline Starch & 107 & 102 \\
\hline Total choline (mg/kg) & 944 & 4250 \\
\hline Total methionine & 9.1 & 9.4 \\
\hline Total cysteine & 5.1 & 5.8 \\
\hline
\end{tabular}

a Low fishmeal diet

${ }^{\mathrm{b}}$ Choline supplemented low fishmeal diet

'Supplied by Kôster Marine Proteins $\mathrm{GmbH}$

${ }^{\mathrm{d} S}$ Supplied by Norsildmel AS

eSupplied by Selecta S/A, Avenida Jamel Ceilio, 2496 - 12th region. SPC, soya protein concentrate

'Supplied by Cargill Nordic

${ }^{9}$ Supplied by DLG Food Grain

${ }^{\text {h }}$ Supplied by HC Handelscenter

'Supplied by Roquette

'Supplied by FF Skagen

k Supplied by Emmelev

'Supplemented to meet the requirements

mInert marker for the evaluation of nutrient digestibility 
Table 2 Growth performance (Mean values with their standard errors)

\begin{tabular}{lllll}
\hline & LF $^{\mathrm{a}}$ & LFC $^{\mathrm{b}}$ & Pooled SEM & $P$-value $^{\mathrm{c}}$ \\
\hline IBW (g) & 364 & 354 & 7.3 & 0.501 \\
Growth (g) & 344 & 418 & 20.3 & $<\mathbf{0 . 0 0 1}$ \\
SGR (\%d-1) & 0.84 & 0.99 & 0.04 & $<\mathbf{0 . 0 0 1}$
\end{tabular}

${ }^{\mathrm{a}}$ Control low fishmeal diet group $(n=70)$

${ }^{\mathrm{b} C h o l i n e ~ s u p p l e m e n t e d ~ l o w ~ f i s h m e a l ~ d i e t ~}(n=68)$

${ }^{\mathrm{c}} P$-values obtained in t-test, values in bold indicate significant differences

between the two treatments

${ }^{d}$ Initial body weight

especific growth rate

choline in enterocyte lipid transport in post-smolt Atlantic salmon.

\section{Results}

\section{Growth performance and nutrient digestibilities}

Growth performance was significantly higher for fish fed the choline supplemented feed (LFC) compared to those fed the unsupplemented basal diet (LF, Table 2). Choline inclusion did not affect apparent digestibility (AD) significantly for any of the nutrients. The average AD $( \pm$ SEM) for the two test diets was $96.1( \pm 0.24)$ for crude lipid, $90.1( \pm 0.19)$ for crude protein and $75.8( \pm 0.65)$ for starch.

\section{Intestinal chyme dry matter and brush border leucine aminopeptidase}

Choline supplementation tended to increase dry matter content of digesta along the intestine (Table 3). The increase was significant for the mid intestine (MI) and distal intestine (DI) sections of the intestine. The trend was clear also for proximal half of the pyloric intstine 1 (PI1)

Table 3 Intestinal dry matter and leucine aminopeptidase activity (LAP) (Mean values with their standard errors)

\begin{tabular}{|c|c|c|c|c|}
\hline & $\mathrm{LF}^{\mathrm{a}}$ & $\mathrm{LFC}^{\mathrm{b}}$ & Pooled SEM & $P$-value \\
\hline \multicolumn{5}{|c|}{ Intestinal dry matter (\%) } \\
\hline PI1 & 9.3 & 10.3 & 0.65 & 0.062 \\
\hline $\mathrm{Pl} 2$ & 11.0 & 12.2 & 0.71 & 0.086 \\
\hline $\mathrm{Ml}$ & 12.9 & 14.5 & 0.67 & 0.005 \\
\hline DI1 & 12.9 & 14.0 & 0.48 & 0.011 \\
\hline $\mathrm{D} 12$ & 11.0 & 12.7 & 0.47 & $<0.001$ \\
\hline \multicolumn{5}{|c|}{$L A P(\mathrm{mmol} / \mathrm{h} / \mathrm{kg} B W)$} \\
\hline PI & 244 & 235 & 16.1 & 0.729 \\
\hline $\mathrm{Dl}$ & 44 & 43 & 3.1 & 0.743 \\
\hline \multicolumn{5}{|c|}{ LAP ( $\mu \mathrm{mol} / \mathrm{h} / \mathrm{mg}$ prot) } \\
\hline PI & 331 & 385 & 25.3 & 0.309 \\
\hline $\mathrm{Dl}$ & 228 & 244 & 17.3 & 0.237 \\
\hline
\end{tabular}

${ }^{a}$ Control low fishmeal diet group $(n=20)$

${ }^{\mathrm{b}}$ Choline supplemented low fishmeal diet $(n=20)$

${ }^{c} P$-values in bold indicate significant differences between the two treatments; italicized values represent trends and PI2 ( $p=0.062$ and 0.086, respectively). Brush border membrane leucine aminopeptidase (LAP) activities for PI and DI are shown in Table 3. There were no significant differences in the enzyme activity between the two treatments either in PI or DI tissue.

\section{Organosomatic indices, intestinal and liver lipid content and histology}

Relative organ weights of the PI, MI, DI and liver (LI) are shown in Fig. 1. Choline supplementation reduced relative weights of PI, MI and LI significantly, but not of DI. Macroscopic observations revealed white and swollen pyloric caeca in most of the sampled individuals fed the LF diet, whereas this observation was not recorded for any of the fish fed the LFC diet (Fig. 2a). Accordingly, the histological examination showed a significantly higher degree of lipid droplet accumulation in the pyloric caeca in fish fed the LF diet compared to those fed the LFC diet (Fig. 2b and c, respectively, $p<0.001$ ). The degree of vacuolation of the enterocytes was $0 \%$ in sampled fish fed the LFC diet compared to $100 \%$ in the LF fed group (Fig. 3). Choline supplementation significantly lowered triacylglycerol (TAG) concentration in the tissue of the PI (Fig. 4, $p=0.024$ ). No significant differences due to supplementation were found for free fatty acids (FFA), monoacylglycerol (MAG), diacylglycerol (DAG) and phospholipid (PL). The histological examination of LI vacuolation did not indicate similar effects of choline supplementation as in the pyloric caeca. No significant differences in the degree of liver vacuolation was found between the two diets $(p=0.867)$. Likewise, calculation of absolute amount of liver lipid (g) did not reveal significant differences $(p=0.867)$ between LFC and LF fed fish, $0.33( \pm 0.04)$ and $0.33( \pm 0.03)$, respectively.

\section{Intestinal gene expression}

Figure 5 illustrates the molecular regulations of the studied genes involved in synthesis of phosphatidylcholine, cholesterol, and lipids, as well as intestinal lipid transport, lipoprotein assembly and secretion. Table 4 presents the results of the effect of choline supplementation on intestinal gene expression. Expression of genes encoding three enzymes involved in the pathway of phosphatidylcholine biosynthesis was analysed. The expression of the pcyt1a gene was significantly down-regulated whereas the effect for chk showed a trend towards down-regulation ( $p=$ 0.068). No significant effect was observed on expression of pemt. Genes involved in cholesterol $(\mathrm{CH})$ transport were also significantly affected in fish fed the choline enriched diet. Niemann-Pick C1 like 1 (npc1l1) and abcg5 were upregulated. Expression of fabp2 homologs, encoding fatty acid transporters, and the transcription factors ppara and ppary were significantly enhanced. Also mgat $2 a$, responsible for TAG re-esterification, was significantly up- 


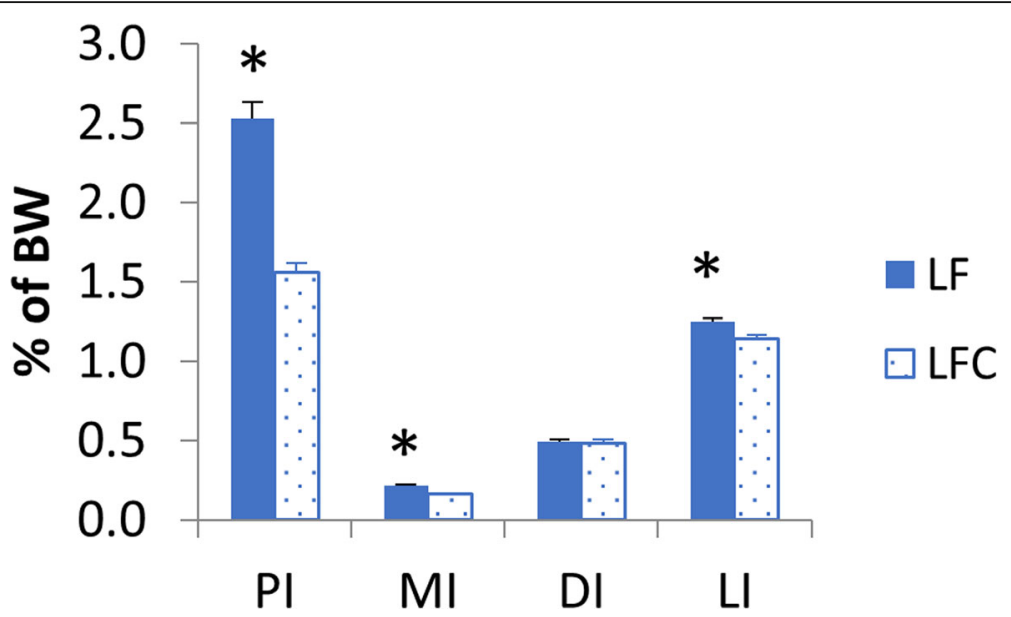

Fig. 1 Organ somatic indices of the intestinal sections, pyloric intestine (PI), mid-intestine (MI), distal intestine (DI) and liver (LI). Values are means (PI $n=20$ and MI, DI and LI $n=30$ ) with standard errors represented by vertical bars. Significant differences $(p<0.05)$ between the LF and LFC group are indicated with *. The inclusion of choline resulted in a significant lower organ somatic index for Pl, Ml and $\mathrm{LI}(p<0.05)$
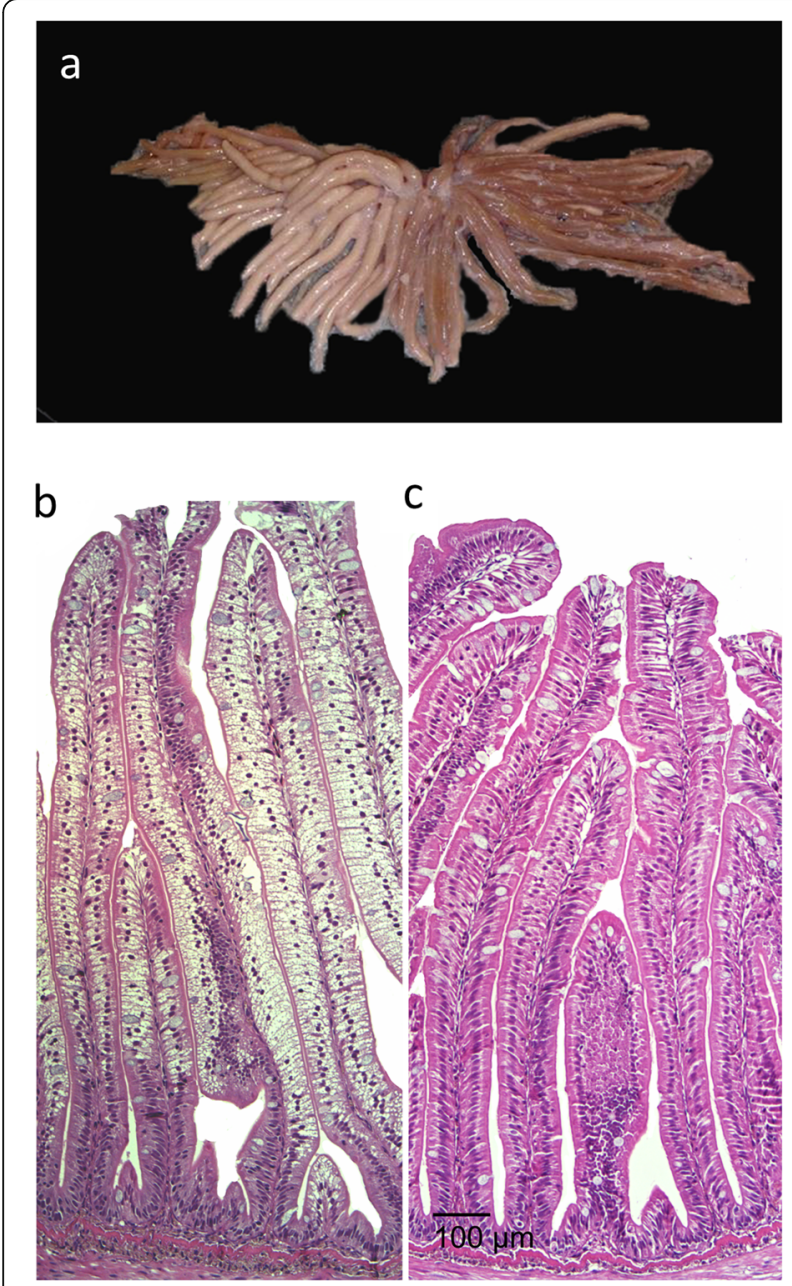

Fig. 2 a example of white pyloric caeca with grossly visible of lipid accumulation. Image credit: Vegard Denstadli. Histological appearance of pyloric caeca in fish fed (b) the low fishmeal diet, LF and (c) the choline supplemented diet, LFC. Scale bare $=100 \mu \mathrm{m}$ regulated. A similar up-regulation was seen for both apoAI and apoAIV, involved in lipoprotein assembly. The general marker for lipid load of non-adipogenic cells, adipophilin/ perilipin 2 (plin2) was down-regulated. The taurine transporter slc6a6 was up-regulated in the choline treated fish.

\section{Hepatic gene expression}

In the microarray analysis (fold change $>1.6, p<0.05$ ), 168 entities were found to be differentially expressed between the two diet groups (Additional file 2). The differentially expressed genes appeared to be distributed among many functional classes, and a search for enriched GO and KEGG terms provided little meaningful information (data not shown). Among the highest responding transcripts, two innate immunity-related lectins (nattectin, c-type mbl-2 protein) were markedly induced by the choline treatment. In contrast, rxr, pmm and $\operatorname{sod} 3$ were down-regulated by choline supplementation. Perilipin 2 (plin2) showed up-regulation in the liver in contrast to the down-regulation found in PI. To further verify the microarray data, $r x r, p m m$, sod 3 and plin 2 were quantified by qPCR (Table 5). In accordance with microarray data, pmm and plin 2 were down- and upregulated, respectively, whereas no differences for $r x r$ and $\operatorname{sod} 3$ were observed with qPCR. The lipoprotein and sterol associated transcripts measured in pyloric caeca were also quantified in liver using qPCR (Table 5). In accordance with the microarray data, we observed no significant changes for any of these transcripts. Altogether, microarray and GPCR data were closely correlated (Person's correlation coefficient: $0.74, p=0.0003$ ).

\section{Blood plasma endpoints}

Most of both the TAG and cholesterol in plasma was present in the high-density lipoprotein (HDL) fraction 


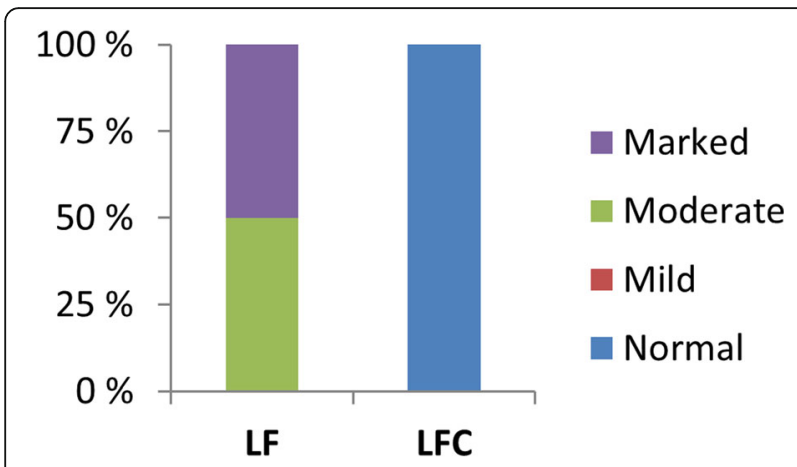

Fig. 3 Contingency charts of the pyloric intestine showing proportions of sampled individuals that scored vacuolation grade "normal", "moderate" and "marked" (none scored "mild"). Fish fed the low fishmeal diet displayed hyper-vacuolated enterocytes. Choline inclusion resulted in normal epithelium. The differences between the diets were significant ( $p<0.05$; Chi-squared test)

independent of treatment and the distribution of TAG and cholesterol among the lipoproteins were similar. Choline supplementation significantly decreased the plasma level of TAG reflecting reductions in HDL and low-densitylipoprotein (LDL) (Table 6). The opposite effect was seen on plasma cholesterol reflecting cholesterol increase in all the lipoprotein fractions. Plasma lathosterol, indicative of the rate of cholesterol synthesis, increased upon choline supplementation. The level of $7 \alpha-$ hydroxycholesterol, a metabolite in cholesterol catabolism and conversion to bile acids, also increased, whereas C4

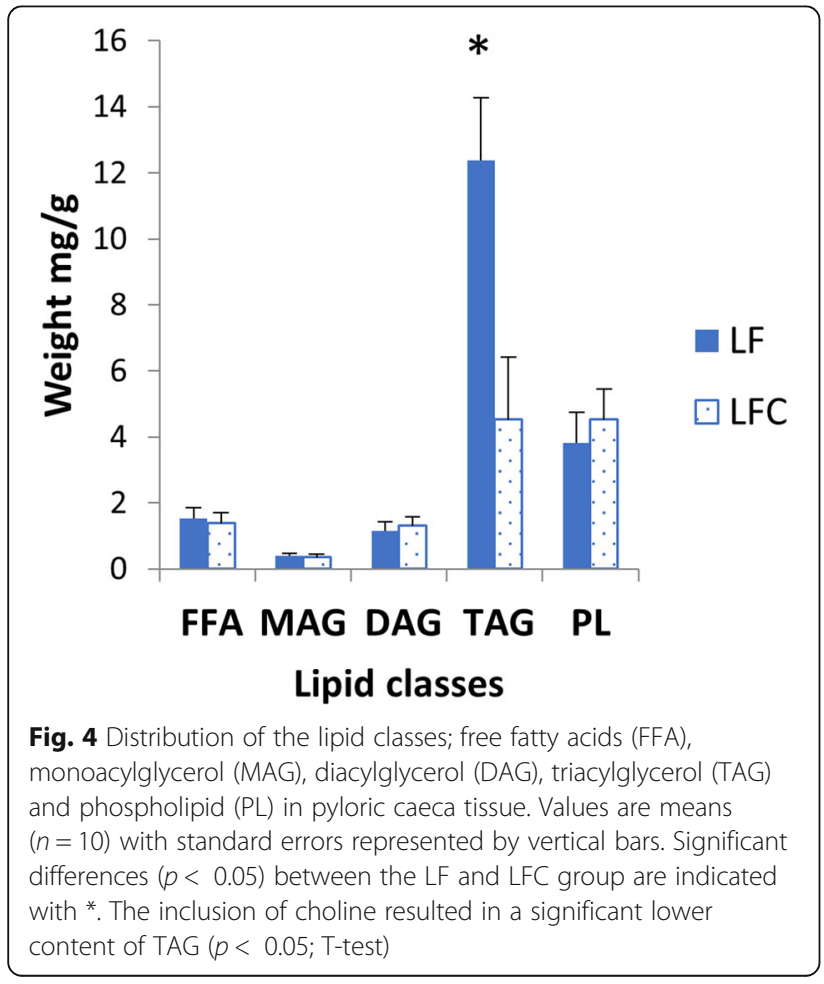

(7 $\alpha$-Hydroxy-4-cholesten-3-one), a later metabolite in the cholesterol catabolism, was not significantly affected. Plasma levels of other catabolic products of cholesterol, i.e. the oxysterols $7 \beta$ - hydroxycholesterol, $7 \beta$-keto-hydroxycholesterol, 24-hydroxycholesterol and 27-hydroxycholesterol were increased by dietary choline supplementation.

\section{Discussion}

In brief, the present study revealed that choline supplementation to a plant based diet, $4.3 \mathrm{~g} / \mathrm{kg}$, improved growth by $18 \%$, without effects on macronutrient digestibilities or other observed indicators of digestive function. The relative weight of the pyloric caeca decreased by $40 \%$ - reflecting a reduction in TAG and was shown histologically as elimination of enterocyte hypervacuolation. On the molecular level the supplementation caused down-regulation of genes involved in the CDPcholine pathway in which phosphatidylcholine is synthesized from free choline and a phosphorylated diglyceride (chk and pcyt1a), but had no significant effect on expression of pemt involved in synthesis of phosphatidylcholine from phosphatidylethanolamine via the PEMT pathway, the second pathway for phosphatidylcholine synthesis. Choline supplementation up-regulated two genes involved in cholesterol transport (abcg5 and npc1l1), as well as genes involved in lipid metabolism and transport (mgat $2 a$ and fabp2), and lipoprotein formation (apoA1 and apoAIV). The reduced intracellular lipid level was reflected in marked suppression of the lipid droplet marker plin2.

The aim of the present study was to elucidate if choline deficiency is a key contributor for LMS, and whether dietary supplementation with choline might prevent development of LMS. Our results clearly affirm these hypotheses. In this respect, our results are in line with the observations of lipid accumulation in Japanese eel fed choline deficient diets [33]. Our observations also highlight the importance of choline in lipid turnover in post-smolt Atlantic salmon, and supply information relevant for later developmental stages.

\section{Choline effects on performance}

Choline supplementation of the feed for Atlantic salmon of the size used in the present study, start weight $362 \mathrm{~g}$ and final weight $740 \mathrm{~g}$, was found to have a great improving effect on SGR, by $18 \%$. Similar improvements have been observed at juveniles stages in Atlantic salmon as well as in other species [32, 34-38]. Several studies have also confirmed the requirement for phospholipid in both freshwater and marine juveniles $[31,34,39,40]$. The $18 \%$ increase in growth rate in fish fed the choline supplemented diet may give great expectations for improvement of efficiency in production of Atlantic salmon. It should, however, be kept in mind, 


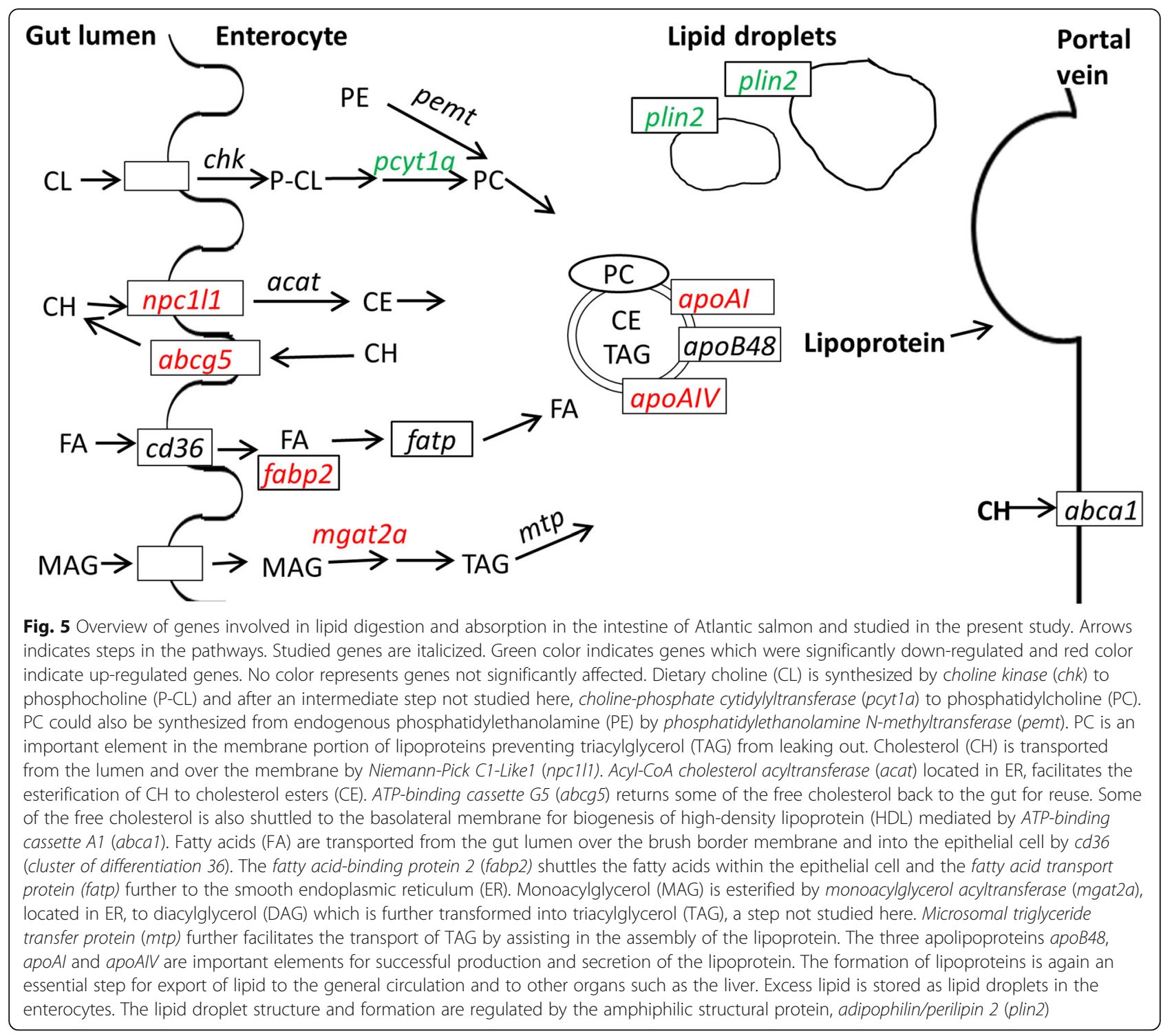

that the SEM indicates that the true difference might be much less, or much higher. Follow-up studies are therefore needed, to find whether similar improvements can be expected in the long run.

\section{Effects of choline on lipid accumulation in the pyloric intestinal tissue}

There is a general understanding that TAG is the primary lipid class in lipid stores [40] and an increased supply of fatty acids promotes TAG synthesis and storage in fat cells where lipid droplets increase in abundance and size [41]. The high TAG levels and the corresponding occurrence of large lipid vacuoles observed in the pyloric caeca of the control fish suffering from LMS in the present study are in line with this. The absence of lipid droplets in pyloric caeca in choline fed fish might also be explained by phosphatidylcholine playing an important role in lipoprotein formation, and therefore in the transport of lipids across cell membranes and an efficient transport of dietary lipids from the pyloric caeca [22, 42-44]. The relatively low TAG level observed in fish fed the choline supplemented feed could also be a result of phosphatidylcholine also acting as a surfactant stabilizing growing lipid droplets and further preventing lipid droplet coalescence [41]. The concomitant alterations in expression of genes involved in phosphatidylcholine synthesis, cholesterol synthesis, lipid droplet formation, lipid transport, and lipoprotein formation and metabolism tested in the present study confirmed the importance of choline in this respect.

The cytidine (CDP)-choline pathway is the main pathway for phosphatidylcholine synthesis from dietary choline [29]. Choline kinase (chk), catalyzing the initial and committing step, showed a tendency to be down-regulated by choline 
Table 4 Gene expression profiling of pyloric caeca samples by qPCR

\begin{tabular}{|c|c|c|c|}
\hline Gen category and function & Gen symbol & Fold change $^{a}$ & $P$-value \\
\hline \multicolumn{4}{|l|}{ Lipid uptake and transport } \\
\hline Fatty acid transporter & $c d 36$ & 1.13 & 0.175 \\
\hline Fatty acid transporter & $f a b p 2 b$ & 1.37 & 0.004 \\
\hline Fatty acid transporter & fabp2a1 & 1.11 & 0.302 \\
\hline Fatty acid transporter & fabp2a2 & 1.01 & 0.962 \\
\hline Fatty acid transporter & fatp & 0.89 & 0.120 \\
\hline Lipoprotein assembly & $m t p$ & 1.12 & 0.259 \\
\hline Lipoprotein component & apoB48 & 1.07 & 0.730 \\
\hline Lipoprotein component & apoAIV & 1.58 & 0.028 \\
\hline Lipoprotein component & apoAl & 1.42 & 0.001 \\
\hline Lipid droplet component & plin2 & 0.273 & $<0.001$ \\
\hline Nuclear receptor - regular of lipid metabolism & ppara & 1.52 & 0.037 \\
\hline Nuclear receptor - regular of lipid metabolism & ppary & 1.38 & 0.024 \\
\hline Resynthesis of triacylglycerols & mgat2a & 1.39 & 0.023 \\
\hline \multicolumn{4}{|l|}{ Phosphatidylcholine synthesis } \\
\hline Choline transporter & slc44a2 & 1.09 & 0.329 \\
\hline Phosphatidylcholine biosynthesis & pemt & 0.95 & 0.486 \\
\hline Phosphatidylcholine biosynthesis & chk & 0.61 & 0.068 \\
\hline Phosphatidylcholine biosynthesis & pcyt1a & 0.58 & 0.004 \\
\hline \multicolumn{4}{|l|}{ Cholesterol metabolism } \\
\hline Bile acid nuclear receptor & fxr & 1.15 & 0.415 \\
\hline Cholesterol biosynthesis & hmgcr & 0.91 & 0.260 \\
\hline Cholesterol efflux transporter & $a b c a 1$ & 0.95 & 0.650 \\
\hline Cholesterol efflux transporter & $\operatorname{abcg} 5$ & 1.61 & 0.004 \\
\hline Cholesterol esterification & acat & 0.95 & 0.677 \\
\hline Cholesterol transporter & $n p c 1 / 1$ & 1.58 & $<0.001$ \\
\hline Nuclear receptor - regular of lipid and sterol metabolism & Ixr & 1.06 & 0.580 \\
\hline Nuclear receptor - regular of lipid and sterol metabolism & srebpl 1 & 0.55 & 0.159 \\
\hline Nuclear receptor - regular of lipid and sterol metabolism & srebp2 & 1.04 & 0.907 \\
\hline Taurine transporter - bile salt metabolism & slc6a6 & 1.39 & 0.001 \\
\hline
\end{tabular}

Values are mean fold change observed in the choline diet fed group in comparison with those in the control group

${ }^{\mathrm{b}} \mathrm{P}$-values in bold indicate significant differences between the two treatments; italicized values represent trends

supplementation, whereas significant down-regulation was found for pcyt1a, regulating the second and rate-limiting step in the CDP-pathway [28, 29]. These results are in agreement with findings presented earlier [8] showing lower expression of chk and pcyt1a in the pyloric caeca of fish fed a high fishmeal diet, supposedly with a higher choline level, compared to the expression in hyper-vacuolated pyloric caeca of fish fed a plant meal based diet with a lower choline level. The down-regulation of chk and pcyt1a, as a result of choline supplementation in the present study, could be an indication that the fish received more than enough choline and that the phosphatidylcholine synthesis was regulated through a negative feed-back control. However, regulation of pcyt1a activity is very complicated with important post translational steps [45]. Further studies of this rate limiting enzyme are therefore needed to understand the impact of the observed effect on pcyt1a. Choline supplementation did not, however, alter the expression of pemt in the present study, which is in agreement with previous studies carried out with mammals which showed that pemt is expressed mainly in the liver [29].

Choline induced the expression of both npc1l1, involved in the absorption of cholesterol from the intestinal lumen into the enterocytes [46] and $a b c g 5$, catalyzing the transport of a proportion of the free cholesterol back to the gut for reuse [47]. As such, choline seemed to promote the circulation and reuse of free cholesterol, also indicated by the increased blood plasma $\mathrm{CH}$ levels in choline fed fish. 
Table 5 Gene expression profiling of liver samples by qPCR

\begin{tabular}{|c|c|c|c|}
\hline Gen category and function & Gen symbol & Fold change $e^{a}$ & $P$-value ${ }^{\mathrm{b}}$ \\
\hline \multicolumn{4}{|l|}{ Lipid uptake and transport } \\
\hline Fatty acid transporter & $c d 36$ & 0.948 & 0.711 \\
\hline Fatty acid transporter & fatp & 0.992 & 0.923 \\
\hline Lipoprotein component & $a p o(B 100)_{\text {liver }}$ & 0.996 & 0.983 \\
\hline Lipid droplet component & plin2 & 1.626 & 0.013 \\
\hline Nuclear receptor - regular of lipid metabolism & ppara & 0.660 & 0.182 \\
\hline Nuclear receptor - regular of lipid metabolism & ppary & 0.973 & 0.834 \\
\hline \multicolumn{4}{|l|}{ Phosphatidylcholine synthesis } \\
\hline Phosphatidylcholine biosynthesis & pemt & 0.998 & 0.988 \\
\hline Phosphatidylcholine biosynthesis & chk & 0.505 & 0.116 \\
\hline Phosphatidylcholine biosynthesis & pcyt1a & 0.923 & 0.597 \\
\hline Cholesterol metabolism & $a b c 1 a 1$ & 0.851 & 0.310 \\
\hline Bile acid nuclear receptor & $f x r$ & 1.154 & 0.265 \\
\hline Cholesterol biosynthesis & hmgcr & 0.936 & 0.479 \\
\hline Cholesterol biosynthesis & cyp7a1 & 0.925 & 0.580 \\
\hline Cholesterol efflux transporter & abcal & 0.855 & 0.289 \\
\hline \multicolumn{4}{|l|}{ Cholesterol efflux transporter } \\
\hline Cholesterol efflux transporter & $a b c g 5$ & 1.063 & 0.601 \\
\hline Cholesterol transporter & npc1/1 & 0.955 & 0.776 \\
\hline Nuclear receptor - regular of lipid and sterol metabolism & Ixr & 0.837 & 0.156 \\
\hline Nuclear receptor - regular of lipid and sterol metabolism & srebpl 1 & 0.944 & 0.851 \\
\hline Nuclear receptor - regular of lipid and sterol metabolism & srebp2 & 1.174 & 0.405 \\
\hline \multicolumn{4}{|l|}{ ROS metabolism / antioxidant } \\
\hline Superoxide dismutation & $\operatorname{sod} 3$ & 0.739 & 0.374 \\
\hline \multicolumn{4}{|l|}{ Nuclear receptor - control of gene transcription } \\
\hline Transcription factor & $r \times r$ & 0.789 & 0.104 \\
\hline \multicolumn{4}{|l|}{ Mannose metabolism } \\
\hline Glycosylation & pmm & 0.759 & 0.029 \\
\hline
\end{tabular}

${ }^{a}$ Values are mean fold change observed in the choline diet fed group in comparison with those in the control group

${ }^{\mathrm{b}} P$-values in bold indicate significant differences between the two treatments; italicized values represent trends

Choline supplementation seemed not to influence the transport of fatty acids across the brush border membrane from gut lumen to the enterocytes and further to ER as no significant alteration of $c d 36$ and fatp expressions were observed. On the other hand, choline seemed to influence the transport of fatty acids within the epithelial cell due to the induced expression of fabp 2 in the choline fed group [48, 49]. The up-regulation of mgat $2 a$ indicates that choline is also important in the synthesis of MAG to DAG, which is an important intermediate for the synthesis of both TAG and phosphatidylcholine [50]. The synthesized TAG is exported from the cells in lipoproteins. Both apoAI and apoAIV are major proteins in enterocyte lipoprotein assembly [51] and were up-regulated with choline supplementation. These results support our hypothesis regarding the importance and key roles of choline for efficient lipid supply and metabolism in salmon and strengthens the suggestion that choline is important for the synthesis and secretion of lipoproteins [10, 22, 27, 42, 52]. A study on rats [53] observed an increased intestinal lipid content and an impaired chylomicron secretion as a result of choline deficiency. These observations support our findings regarding the importance of choline for proper lipid metabolism.

Another important observation was the decreased expression of plin2, a general marker for the lipid load of non-adipogenic cells [54]. In humans, plin2 has been suggested as a marker for detection of lipid droplets in tissues, which further are associated with various diseases such as hepatocyte steatosis [55]. Plin2 has also been reported to coat cytoplasmic lipid droplets in 
Table 6 Blood plasma variables

\begin{tabular}{|c|c|c|c|c|}
\hline & $\mathrm{LF}^{\mathrm{a}}$ & $\mathrm{LFC}^{\mathrm{b}}$ & Pooled SEM & $P$-value ${ }^{c}$ \\
\hline Glucose $(\mathrm{mmol} / \mathrm{L})^{d}$ & 5.3 & 5.9 & 0.22 & $<0.001$ \\
\hline Free Fatty Acids $(\mathrm{mmol} / \mathrm{L})^{d}$ & 0.27 & 0.25 & 0.02 & 0.35 \\
\hline \multicolumn{5}{|l|}{ Lipoptoteins } \\
\hline Total CH (mmol/L) ${ }^{d}$ & 8.3 & 11.1 & 1.74 & $<0.001$ \\
\hline $\mathrm{HDL}-\mathrm{CH}^{\mathrm{e}}$ & 7.5 & 8.9 & & \\
\hline $\mathrm{LDL}-\mathrm{CH}^{\mathrm{e}}$ & 1.3 & 1.5 & & \\
\hline VLDL-CH & 0.1 & 0.3 & & \\
\hline Total TAG $(\mathrm{mmol} / \mathrm{L})^{d}$ & 3.3 & 2.5 & 0.27 & 0.01 \\
\hline HDL-TAG & 3.2 & 2.4 & & \\
\hline LDL-TAG ${ }^{e}$ & 1 & 0.7 & & \\
\hline VLDL-TAG ${ }^{e}$ & 0.5 & 0.8 & & \\
\hline Bile salts $(\mu \mathrm{mol} / \mathrm{l})^{d}$ & 20 & 19 & 8.47 & 0.822 \\
\hline Sitosterol $(\mu \mathrm{g} / \mathrm{ml})^{f}$ & 71 & 61 & 6.98 & 0.204 \\
\hline Campesterol $(\mu \mathrm{g} / \mathrm{ml})^{f}$ & 188 & 224 & 27.4 & 0.342 \\
\hline Lathosterol $(\mu \mathrm{g} / \mathrm{ml})^{f}$ & 3.8 & 9.2 & 0.48 & $<0.001$ \\
\hline $\mathrm{C} 4(\mu \mathrm{g} / \mathrm{ml})^{f}$ & 0.01 & 0.01 & 0.02 & 0.921 \\
\hline \multicolumn{5}{|l|}{ Oxysterols $(\mathrm{ng} / \mathrm{ml})^{\mathrm{e}}$} \\
\hline 7a-hydroxy-CH & 130 & 295 & & \\
\hline $7 \beta$-hydroxy-CH & 37 & 139 & & \\
\hline 7-keto-hydroxy-CH & 101 & 538 & & \\
\hline 24-hydroxy-CH & 2.2 & 4 & & \\
\hline 25-hydroxy-CH & 5 & 5 & & \\
\hline 27-hydroxy-CH & 21 & 33 & & \\
\hline
\end{tabular}

Low fishmeal diet

${ }^{\mathrm{b}}$ Choline supplemented low fishmeal diet

${ }^{c} P$-values in bold indicate significant differences between the two treatments; italicized values represent trends

${ }^{\mathrm{d}}$ Measured for $\mathrm{n}=20$ per diet

eLipoprotein and oxysterol profiles were measured in pooled samples of $n=5$ per diet

${ }^{\mathrm{f}}$ Measured for $\mathrm{n}=10$ per diet. Mean values with their standard errors

enterocytes of chronic high-fat fed mice [54]. The apparent correlation between plin2 expression and degree of enterocyte hyper-vacuolation observed in the current and previous studies [56], suggest that plin 2 may serve as a marker for intestinal lipid accumulation and steatosis in fish.

\section{Effects of choline on liver}

The choline fed fish had significantly lower hepatosomatic index than the control, but this was not reflected in lower content of lipid, nor in histological apparent vacuolation. Both diets resulted in relatively high degree of lipid accumulation. This is in accordance with previous observations in gibel carp [32] and red drum [57] showing that dietary choline deficiency did not cause an increased accumulation of liver lipid. On the other hand, studies on common carp [58], lake trout [30], rainbow trout [31] and blunt snout bream [59] reported fatty livers in fish fed choline deficient diets. In the present study, choline supplementation caused only minor effects on the hepatic transcriptome and no genes related to lipid metabolism showed altered expression. Collectively, the lack of response to choline supplementation in liver is in sharp contrast to the marked changes observed in the intestine and clearly points towards a focus on intestinal responses in future studies of lipid accumulation and choline requirements in salmon.

\section{Choline effects on plasma indicators}

Very low-density lipoprotein (VLDL) synthesis and assembly is regulated by the availability of triglycerides [60-63] and it seems from the tendency of the enhanced amount of both VLDL-TAG and VLDL-CH observed in the choline group that choline increased the VLDL synthesis and assembly. Even though an increase in VLDLTAG was observed did the total level of TAG decrease in plasma in fish fed the choline enriched diet. The reduction was a result of reduced TAG in both HDL and LDL which could indicate that the lipids were successfully extracted from VLDL in the peripheral tissues [64]. A similar decrease in TAG level in plasma has been observed for juvenile lobsters [65] and cobia larvae [39] fed soy lecithin. Niu et al. [39] further suggested that this was a result of a positive effect of phospholipids on lipoprotein lipase and hepatic lipase activities for TAG uptake in liver and further distribution to other tissues. Choline also seemed to increase HDL's, in addition to VLDL and LDL's, capacity to bind and transport cholesterol due to the higher cholesterol amount. The present study further supports previous observations [66-68] showing that HDL is the most abundant lipoprotein carrying the main load of both cholesterol and TAG. The increase of cholesterol bound to HDL in the choline supplemented group could be a result of higher levels of phospholipids incorporated into the HDL, which in a study with rat, was shown to play a key role in modulating cholesterol efflux (transport and re-use of cholesterol) [69]. Phospholipid levels in the lipoproteins were not analysed in the present study, so this should be investigated in further studies.

\section{Conclusion}

Choline is an essential nutrient for Atlantic salmon, even after early developmental stages. Plant based diets must be supplemented with choline to ensure normal uptake, metabolism, and export of lipids across the intestinal mucosa.

\section{Methods}

\section{Diets}

A low fishmeal, high plant diet (LF) was used as a reference diet, containing $10 \%$ of a $50 / 50$ mix of Nordic LT 
fishmeal from the North Atlantic and Super Prime fishmeal from Peru. The total lipid content was $70 \%$ rape seed oil and 30\% fish oil. The choline supplemented diet (LFC) was made by supplementing the LF diet with $4 \mathrm{~g} / \mathrm{kg}$ of choline chloride. The diets contained approximately the same amount of methionine and cysteine. Table 1 shows diet formulation and analysed chemical composition. Both diets were supplemented with standard vitamin and mineral premixes in accordance with NRC guidelines (2011) and BioMar standards to meet requirements. Yttrium oxide $(0.5 \mathrm{~g} / \mathrm{kg})$ was added as inert marker for estimation of nutrient apparent digestibility. The two experimental diets were produced by extrusion (feed pellet size $6 \mathrm{~mm}$ ) at BioMar Feed Technology Centre (Brande, Denmark) using a BC 45 twin screw extruder (Clextral, France).

\section{Experimental animals and conditions}

Atlantic salmon (Salmo salar L., post smolt, Sunndalsøra breed) with mean initial weight of $362 \mathrm{~g} \pm 95$ (mean \pm SD) were pit tagged, weighed individually, and randomly allocated into four fiberglass tanks with $270 \mathrm{l}$ of saltwater, two replicate tanks per diet, 35 fish in each. Each tank was supplied with flow through seawater. Salinity ranged between 32 and $33 \mathrm{~g} / \mathrm{l}$. The water flow was increased accordingly to the increase in biomass and to maintain oxygen saturation at any time above $80 \%$. The oxygen content of the outlet water was monitored once a week or more often in periods with larger temperature variations. Temperature varied between 7.0 and $14.5{ }^{\circ} \mathrm{C}$ during the experimental period (from July to September), with an average of $9.4{ }^{\circ} \mathrm{C}$. A $24 \mathrm{~h}$ light regime was employed during the experimental period. The fish were fed continuously using disc feeders aiming at an excess feeding of $15 \%$ during the trial period. Equipment for recording feed waste and hence feed intake was not available for the present experiment.

\section{Sampling}

After 79 days, feeding was terminated. Weight and length were recorded for all fish. From each tank ten fish were anaesthetized with tricaine methane-sulfonate (MS-222). Blood was sampled from the caudal vein in vacutainers with lithium heparin. The vacutainers were stored on ice until plasma preparation. Plasma, $2 \mathrm{~mL}$ aliquots, was frozen in liquid nitrogen and stored at $80^{\circ} \mathrm{C}$. Following blood sampling the fish were killed by a sharp blow to the head and opened ventrally. The gastro-intestinal tract was removed from the abdominal cavity, cleared of other organs and adipose tissue, and sectioned as follows. Pyloric intestine (PI): the section from the pyloric sphincter to the most distal pyloric caeca; mid intestine (MI): from the distal end of PI and proximal to the increase in intestinal diameter; distal intestine (DI): from the distal end of MI to the anus. The intestinal wall tissue of PI and DI was collected and weighed, whereas the digesta from these two sections were each split into two samples, i.e. the proximal half (PI1 and DI1, respectively) and distal half (PI2 and DI2, respectively). The intestinal samples were snap frozen in liquid nitrogen and stored at $-80^{\circ} \mathrm{C}$. The liver (LI) was also sampled and weighed. Another five fish per tank were euthanized and killed for sampling of LI and PI for histological and gene expression analyses. The 20 fish remaining in each tank were stripped for faeces as described by Austreng [70]. They were then fed for one more week for an additional stripping. The fecal samples were pooled for each tank, frozen immediately after stripping $\left(\mathrm{N}_{2}\right)$ and stored at $-80^{\circ} \mathrm{C}$ until analysis. Tissues sampled for histological examination were fixed in $10 \%$ neutral buffered formalin ( $4 \%$ formaldehyde). Samples for gene expression analyses were rinsed in sterile saline water, submerged in RNAlater, incubated at $4{ }^{\circ} \mathrm{C}$ for $24 \mathrm{~h}$ and subsequently stored at $-40^{\circ} \mathrm{C}$ until analysis.

\section{Histology}

Pyloric caeca and liver samples were processed at the Norwegian University of Life Sciences (NMBU) using standard histological techniques: dehydration in ethanol, clearing in xylene, and embedding in paraffin before sectioning $(5 \mu \mathrm{m})$. Hematoxylin and eosin were used for tissue staining. The samples were evaluated for enterocyte vacuolation blinded in a randomized order using a light microscope. Vacuolation was assessed based on appearance of lipid-like vacuoles, swelling and irregularity of the cells, and condensation of the nuclei. Vacuolation was assessed semi-quantitatively as the proportion of total tissue affected: normal $(\leq 10 \%)$, mild $(10-25 \%)$, moderate $(25-50 \%)$ or marked $(\geq 50 \%)$ and presented as percentage of vacuolated enterocytes (Fig. 6).

\section{RNA extraction}

Total RNA was extracted from pyloric caeca samples ( $30 \mathrm{mg}$ ) using a Ultraturrax homogenizer, TRIzol $^{\circ}$ reagent (Invitrogen, ThermoFisher Scientific) and chloroform according to the manufacturer's protocol. Obtained RNA was DNase treated $\left(\mathrm{TURBO}^{\mathrm{in}}\right.$, Ambion, ThermoFisher Scientific) and purified with PureLink RNA mini kit (Invitrogen, ThermoFisher Scientific). Total RNA from liver samples $(\sim 30 \mathrm{mg})$ were also extracted using Trizol $^{\circ}$ /chloroform whereas the homogenization was carried out using a FastPrep-24 (MP Biomedicals) before the samples were purified with PureLink RNA mini kit including an on-column DNase treatment according to the manufacturer's protocol. The integrity of the RNA from pyloric caeca samples were assessed by gel electrophoresis, and in addition selected samples were verified with a 2100 Bioanalyzer using a RNA Nano Chip (Agilent Technologies). All liver samples were evaluated by 


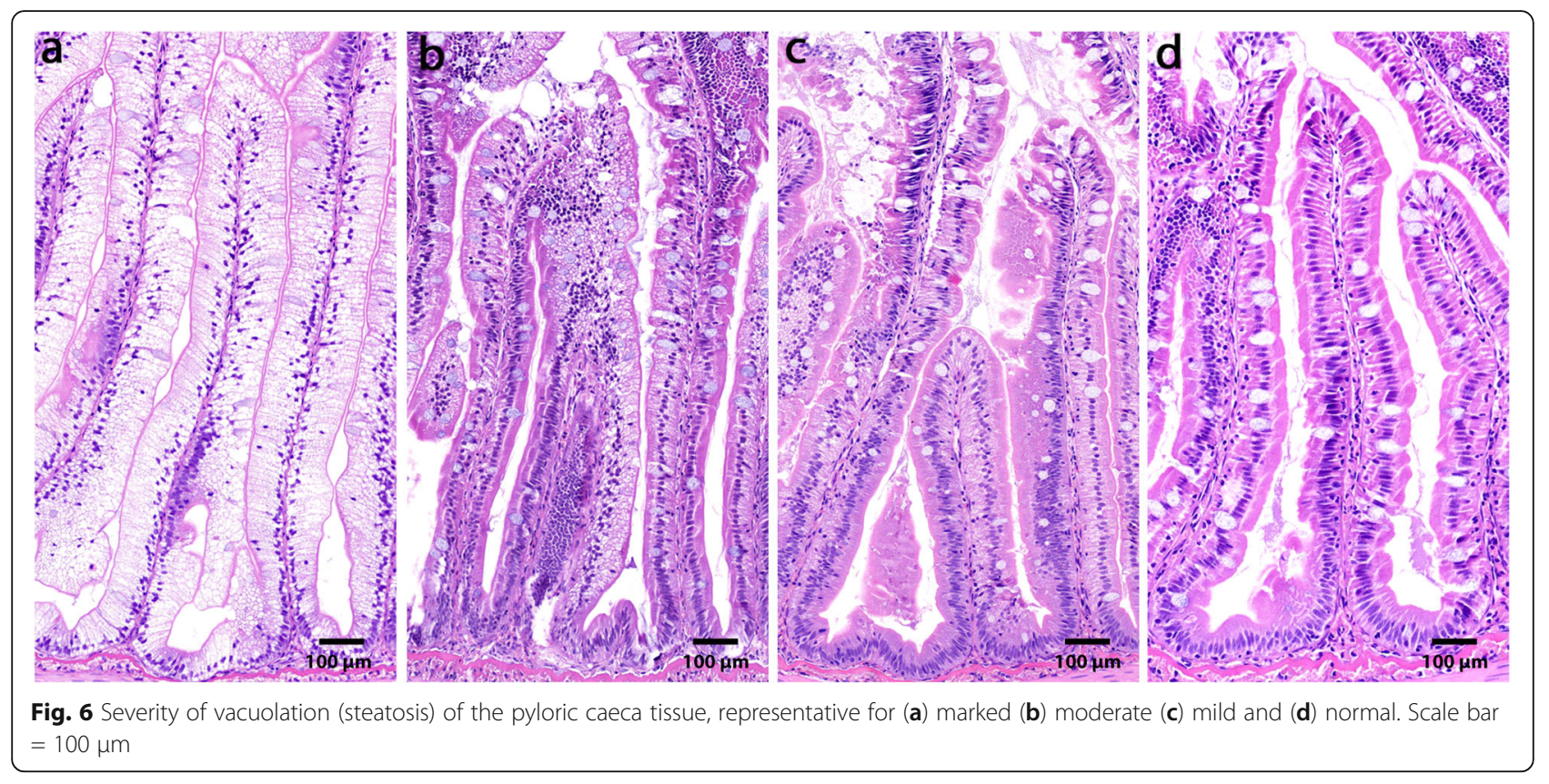

Bioanalyzer. RIN values for both pyloric caeca and liver samples were all $>8$. RNA purity and concentrations were measured using the NanoDrop ND-1000 Spectrophotometer (NanoDrop Technologies). Total RNA was stored at $-80^{\circ} \mathrm{C}$ until use.

\section{Microarrays}

A two-colour microarray design was used for liver transcriptome profiling. Samples from five fish per treatment were labeled with fluorescent $\mathrm{Cy} 3$ and hybridized against a common reference sample (pool of 10 individual fish fed a fishmeal-based diet) labeled with fluorescent Cy5. Nofima's Atlantic salmon $15 \mathrm{k}$ oligonucleotide microarray SIQ-6 (GEO Omnibus GPL16555) was manufactured by Agilent Technologies (Santa Clara, CA USA). Reagents and equipment were from the same source unless indicated otherwise. RNA amplification and labelling were performed with a Two-Colour Quick Amp Labelling Kit and Gene Expression Hybridization kit was used for fragmentation of labelled RNA. A total of $200 \mathrm{ng}$ RNA was used as input for each reaction. After hybridization in an oven over night $\left(17 \mathrm{~h}, 65^{\circ} \mathrm{C}, 10 \mathrm{rpm}\right.$ rotation speed), arrays were washed with Gene Expression Wash Buffers 1 and 2 and scanned with a GenePix 4100A (Molecular Devices, Sunnyvale, CA, USA). GenePix Pro 6.0 was used for spot to grid alignment, assessment of spot quality, feature extraction and quantification. STARS were used to carry out the subsequent bioinformatics data analysis [71]. Low quality spots were flagged by GenePix and filtrated away before Lowess normalization of $\log _{2}$-expression ratios (ER) was performed. Genes that passes quality control in at least four samples per group were included in subsequent analyses. The differentially expressed genes (DEG) were selected by the following criteria: fold difference $>1.6$ and $p<0.05$ (T-test). Enrichment of GO and KEGG terms in the list of DEG was assessed with Yates' corrected chi-square using all probes that passed quality control as reference. Enriched terms corresponding to at least five differentially expressed genes were selected.

\section{Quantitative real-time PCR (qPCR)}

Quantification of hepatic gene expression by qPCR was conducted to validate the microarray results and to examine particular genes of interest in detail. qPCR was also used for quantification of genes related to lipid and sterol metabolism and transport in pyloric caeca. Assays were carried out in accordance to the MIQE standards [72]. First strand cDNA synthesis was carried out using four fish from each tank giving a total of eight fish per treatment, and Superscript III in $20 \mu \mathrm{L}$ reactions (Invitrogen) with total RNA $(0.8 \mu \mathrm{g})$ and oligo $(\mathrm{dT})_{20}$ primers were used. Negative controls were performed in parallel by omitting RNA or enzyme. Obtained cDNA was diluted 1:10 before use and stored at $-20^{\circ} \mathrm{C}$. Quantitative PCR primers were obtained from literature or designed using Primer3web version 4.0.0 (http://bioinfo.ut.ee/pri mer3/). Detailed information of the primers is shown in Additional file 1. PCR reaction efficiency (E) for each gene assay was determined separately for both pyloric caeca and liver using 2-fold serial dilutions of randomly pooled cDNA. A LightCycler 480 (Roche Diagnostics) was used for DNA amplification and analysis of the expression of individual gene targets. Each $10 \mu \mathrm{l}$ DNA 
amplification reaction contained $2 \mu \mathrm{l}$ PCR-graded water, $2 \mu \mathrm{l}$ of 1:10 diluted complementary DNA template, $5 \mu \mathrm{l}$ of LightCycler 480 SYBR Green I Master (Roche Diagnostics) and $0.5 \mu \mathrm{l}$ of each forward and reverse primer. Each sample was assayed in duplicate in addition to a no template control. The three-step qPCR program included an enzyme activation step at $95^{\circ} \mathrm{C}$ for $5 \mathrm{~min}$ followed by 40 or 45 cycles (depending on the individual gene tested) of $95^{\circ} \mathrm{C}(10 \mathrm{~s}), 58,60$ or $63^{\circ} \mathrm{C}$ (10 s depending on the individual gene tested) and $72{ }^{\circ} \mathrm{C}(15 \mathrm{~s})$. Quantification cycle $(\mathrm{Cq})$ values were calculated using the second derivative method. The PCR products were evaluated by analysis of melting curve and by agarose gel electrophoresis to confirm amplification specificity. All primer pairs gave a single band pattern on the gel for the expected amplicon of interest in all reactions. For target gene normalization, actb, ef1a, gapdh, rnapolII and rps 20 were evaluated for use as reference genes by ranking relative expression levels according to their stability, as described previously [73]. For liver samples, rnapolII was used as normalization factor, whereas gapdh was used for pyloric caeca. Relative expression of target genes was calculated using the ${ }^{\Delta{ }^{\Delta}} \mathrm{CT}$ method [74].

\section{Chemical analyses}

Diets and faecal samples were analysed for dry matter (after heating at $105^{\circ} \mathrm{C}$ for $16-18 \mathrm{~h}$ ), ash (combusted at $550^{\circ} \mathrm{C}$ to constant weight), crude protein (by the semimicro-Kjeldahl method, Kjeltec-Auto System, Tecator, Höganäs, Sweden), lipid (diethylether extraction in a Fosstec analyzer (Tecator) after HCL-hydrolysis), starch (measured as glucose after hydrolysis by alpha-amylase (Novo Nordisk A/S, Bagsvaerd, Denmark) and amyloglucosidase (Bohringer Mannheim $\mathrm{GmbH}$, Mannheim, Germany), followed by glucose determination by the "Glut-Dh method" (Merck Darmstadt, Germany)), gross energy (using the Parr 1271 Bomb calorimeter, Parr, Moline, IL, USA) and yttrium (by inductivity coupled plasma (ICP) mass-spectroscopy as described by Refstie et al. [75]. The plasma variables; free (non-esterified) fatty acids, cholesterol and total triacylglycerides were analysed according to standard procedures at the Central Laboratory of the Norwegian University of Life Sciences (NMBU). Lipoprotein profile analyses (HDL, LDL and VLDL) in plasma were carried out by size exclusion chromatography and measurements of cholesterol and triglycerides on-line using microliter sample volumes as described by Parini et al. [76]. Isotope dilution mass spectrometry as described by Lund et al. [77] was used for analyzing lathosterol. $7 \alpha$-hydroxy-4-cholesten-3-one (C4) was analyzed by isotope dilution and combined HPLC-MS as described by Lövgren-Sandblom et al. [78]. Plasma levels of oxysterols, sitosterol and camposterol were analyzed by isotope dilution and combined GC-MS after hydrolysis as described by Dzeletovic et al. [79] for the first mentioned and by Acimovic et al. [80] for the last two mentioned. The lipid classes free fatty acids (FFA), monoacylglycerol (MAG), diacylglycerol (DAG), triacylglycerol (TAG) and phospholipid (PL) in the pyloric caeca were extracted using the Folch procedure [81], then analysed using HPTLC Silica gel $60 \mathrm{~F}$ plates. DigiStore 2: documentation was used for visual documentation and the integration program WinCats was further used for calculating the amount of the lipid classes.

\section{Enzyme analyses}

Brush-border membrane enzyme activity were analysed by measuring the activity of the enzyme leucine aminopeptidase (LAP; EC 3.4.11.1) in intestinal tissue homogenates. The homogenates were prepared from tissue thawed on ice-cold tris-mannitol buffer $(1: 20 \mathrm{w} / \mathrm{v})$ containing the serine proteinase inhibitor 4-[2-Aminoethyl] benzensulfonylfluoride HCL (Pefabloc ${ }^{\circ}$ SC; Pentapharm Limited). LAP activity was then determined colorimetrically with a kit (Sigma procedure no. 251) using Lleucine- $\beta$-napthylamide as substrate.

\section{Calculations}

Growth of the fish was calculated as specific growth rate (percent growth per day): SGR $=((\ln \mathrm{FBWg} / \ln \mathrm{IBWg}) /$ D) $X 100$. IBW and FBW are the initial and final body weight (tank means) and D is number of feeding days. Organ somatic index was calculated as percentages of the weight of the organ in relation to body weight. Apparent digestibilities (AD) of main nutrients was estimated by using $\mathrm{Y}_{2} \mathrm{O}_{3}$ [82] as an inert marker and calculated as: $\mathrm{AD}_{n}=100-\left(100 \mathrm{X}\left(\mathrm{M}_{\text {feed }} / \mathrm{M}_{\text {faeces }}\right) \mathrm{X}\right.$ $\left(\mathrm{N}_{\text {feed }} / \mathrm{N}_{\text {faeces }}\right)$ ), where $\mathrm{M}$ represents the percentage of the inert marker in feed and faeces and $\mathrm{N}$ represents the percentage of a nutrient in feed and faeces.

\section{Statistical analysis}

The diets in the present study were part of a larger trial. To obtain the best estimate of variance of tank means (SEM), results from all treatments were included. The other results of the experiment are published elsewhere $[66,67]$. Tank was the experimental unit for all responses except for the histological observations for which the individual fish were the unit. Statistical analyses were performed using SAS (SAS Institute Inc., Cary, NC, USA). Data was analysed using the General Linear Model procedure with diets and tanks as class variables. Specific differences were evaluated by Duncan's test. The level of significance was set to $P<0.05$, and $P$-values between 0.05 and 0.1 were considered as indications of effects and mentioned as trends. All data are means \pm SEM. A Chi-squared test was used for analyzing histology data. 


\section{Supplementary information}

Supplementary information accompanies this paper at https://doi.org/10. 1186/s12917-020-2252-7.

Additional file 1. Primer pair sequences, efficiency, amplicon size and annealing temperature for the genes used for real-time PCR.

Additional file 2. Differentially expressed genes between hepatic transcriptomes of fish fed the low fishmeal diet (LF) and fish fed the choline supplemented diet (LFC).

\section{Abbreviations}

AD: Apparent digestibility; DAG: Diacylglycerol; DI: Distal intestine; DI1: Proximal half of distal intestine; DI2: Distal half of distal intestine; FFA: Free fatty acids; HDL: High-density lipoproteins; IBW: Initital body weight; LAP: Leucine aminopeptidase activity; LDL: Low-density lipoproteins; LF: Low fishmeal; LFC: Choline supplemented low fishmeal; LI: Liver; LMS: Lipid malabsorption syndrome; MAG: Monoacylglycerol; MI: Mid intestine; OSI: Organosomatic indices; PI: Pyloric intestine; PI1: Proximal half of pyloric intestine; PI2: Distal half of pyloric intestine; PL: Phospholipid; qPCR: Quantitative real-time polymerase chain reaction; SGR: Specific growth rate; TAG: Triacylglycerol; VLDL: Very low-density lipoproteins

\section{Acknowledgements}

Thanks to the technicians at NOFIMA Research Station at Sunndalsøra for excellent fish care and management. We would furthermore like to thank Ellen Hage, laboratory technician at Norwegian University of Life Science (NMBU) and Anita Lövgren-Sandblom at Karolinska University Hospital, for the valuable technical assistance and Marie Hillestad (BioMar) for the contribution in the study design, Kjell Måsøval (BioMar) for the contribution in the study design and feed formulation and Vegard Denstadli (BioMar) for professional support.

\section{Authors' contributions}

The authors' contributions were as follows: A.K.G.H: experimental design, sampling, qPCR, data evaluation and interpretation and manuscript development, T.M.K: microarray, qPCR and manuscript review, A.K; microarray and manuscript review, I.B: biochemistry analyses, data interpretation and manuscript revision, M.P: experimental design, sampling and histology, Å.K: leadership, experimental design, data evaluation and interpretation and manuscript review. All authors read and approved the final manuscript.

\section{Funding}

The present work was partly funded by BioMar AS and The Research Council of Norway through the Industrial Ph. D Scheme (project \# 223108). The funding body participated in study design, but had no role in data collection, analysis and interpretation, decision to publish, or preparation of the manuscript.

\section{Availability of data and materials}

The datasets used and/or analysed during the current study are available from the corresponding author on reasonable request. The datasets generated and/or analysed during the current study are available in the National Center for Biotechnology Information (NCBI) Gene Expression Omnibus NCBI repository, with accession no. GSE51887.

\section{Ethics approval and consent to participate}

Rearing of the fish (Atlantic salmon, Salmo salar, Sunndalsøra breed) were conducted at Nofima's Research Station at Sunndalsøra, which is a research facility approved by Norwegian Animal Research Authority (NARA) and operates in accordance with Norwegian Regulations of 17th of June 2008 No. 822: Regulations relating to Operation of Aquaculture Establishments (Aquaculture Operation Regulations). Trial fish were treated in accordance with the Aquaculture Operation Regulations during the trial. Fish were randomly sampled, anaesthetized and killed by a sharp blow to the head, in accordance with the Norwegian Animal Welfare act. No surgical manipulation of live fish was conducted, and tissue samples were only retrieved from euthanized fish. Ingredients commonly used in commercial diets were used in experimental diets and do not cause the fish any apparent distress. No NARA approval was required according to $\$ 2$ of the Norwegian Regulation on Animal Experimentation.

\section{Consent for publication}

Not applicable.

\section{Competing interests}

The present study was partly funded by BioMar AS. Co-author Anne Kristine Hansen is employed by BioMar.

\section{Author details}

${ }^{1}$ Biomar AS, Havnegata 9, 7010 Trondheim, Norway. ${ }^{2}$ Department of Paraclinical Sciences, Faculty of Veterinary Medicine, Norwegian University of Life Sciences, Oslo, Norway. ${ }^{3}$ Nofima AS, Ås, Norway. ${ }^{4}$ Department of Laboratory Medicine, Division for Clinical Chemistry, Karolinska University Hospital, Huddinge, Sweden. ${ }^{5}$ Present Address: US Fish \& Wildlife Service, Northeast Fishery Center, Lamar Fish Health Center, Lamar, PA 16848, USA.

Received: 9 May 2019 Accepted: 20 January 2020

Published online: 31 January 2020

\section{References}

1. NRC. Nutrient Requirements of Fish and Shrimp. Washingt DC: Natl Acad Press; 2011. p. 102-34. and 186-220

2. Hanche-Olsen R, Brunvold L, Hillestad M, Lysne H, Penn M, Løland A. Sluttrapport: Nedsatt Tarmhelse Og Forekomst Av Flytefeces Hos Laks (In Norwegian). 2013. https://www.fhf.no/prosjektdetaljer/?projectNumber= 900722. Accessed 14 Mar 2019.

3. Penn M. Lipid malabsorption in Atlantic Salmon - the recurring problem of floating feces; 2011. p. 6-11. https://docplayer.me/3098420-Nov-2011tarmhelse-fiskehelse.htm

4. Elvis M, Chikwati YL, Wang J, Zhou W, Hage E, Præsteng K, Kortner TM, Torres AJ, Gajardo K, Løkka G, Aru V, Khakimov B, Engelsen SB, Bjørgen H, Koppang EO, Gerd AK. Gut health monitoring during the seawater phase of farmed Atlantic salmon in different production regions of Norway - the GutMatters project. In: 8th International Symposium on Aquatic Animal Health; 2018.

5. Dias J, Alvarez MJ, Arzel J, Corraze G, Diez A, Bautista JM, et al. Dietary protein source affects lipid metabolism in the European seabass (Dicentrarchus labrax). Comp Biochem Physiol A Mol Integr Physiol. 2005; 142:19-31. https://doi.org/10.1016/j.cbpb.2005.07.005.

6. Kaushik SJ, Seiliez I. Protein and amino acid nutrition and metabolism in fish: current knowledge and future needs. Aquac Res. 2010;41:322-32. https://doi.org/10.1111/j.1365-2109.2009.02174.x.

7. Torstensen BE, Espe M, Stubhaug I, Lie $\varnothing$. Dietary plant proteins and vegetable oil blends increase adiposity and plasma lipids in Atlantic salmon (Salmo salar L.). Br J Nutr. 2011;106:633-47. https://doi.org/10.1017/ S0007114511000729.

8. Gu M, Kortner TM, Penn M, Hansen AK. Effects of dietary plant meal and soya-saponin supplementation on intestinal and hepatic lipid droplet accumulation and lipoprotein and sterol metabolism in Atlantic salmon (Salmo salar L.). Br J Nutr. 2014;111:432-44.

9. Olsen RE, Myklebust R, Ring $\varnothing$, Mayhew TM. The influences of dietary linseed oil and saturated fatty acids on caecal enterocytes in Arctic char (Salvelinus alpinus L.): a quantitative ultrastructural study. Fish Physiol Biochem. 2000;22:207-16.

10. Olsen RE, Dragnes BT, Myklebust R, Ring $\varnothing$ E. Effect of soybean oil and soybean lecithin on intestinal lipid composition and lipid droplet accumulation of rainbow trout, Oncorhynchus mykiss Walbaum. Fish Physiol Biochem. 2003;29:181-92.

11. Santigosa E, García-Meilán I, Valentín JM, Navarro I, Pérez-Sánchez J, Gallardo MÁ. Plant oils' inclusion in high fish meal-substituted diets: effect on digestion and nutrient absorption in gilthead sea bream (Sparus aurata L.). Aquac Res. 2011;42:962-74. https://doi.org/10.1111/j.1365-2109.2010.02679.x.

12. Jordal AO, Torstensen BE, Tsoi S, Tocher DR, Lall SP, Douglas SE. NutrientGene Interactions Dietary Rapeseed Oil Affects the Expression of Genes Involved in Hepatic Lipid Metabolism in Atlantic Salmon (Salmo salar L.). J Nutr. 2005;135:2355-61.

13. Kennedy SR, Bickerdike R, Berge RK, Dick JR, Tocher DR. Influence of conjugated linoleic acid (CLA) or tetradecylthioacetic acid (TTA) on growth, lipid composition, fatty acid metabolism and lipid gene expression of rainbow trout (Oncorhynchus mykiss L.). Aquaculture. 2007:272:489-501. https://doi.org/10.1016/j.aquaculture.2007.06.033. 
14. Trattner S, Ruyter B, Østbye TK, Gjøen T, Zlabek V, Kamal-Eldin A, et al. Sesamin increases alpha-linolenic acid conversion to docosahexaenoic acid in atlantic salmon (Salmo salar L.) hepatocytes: role of altered gene expression. Lipids. 2008;43:999-1008. https://doi.org/10.1007/s11745-008-3229-7.

15. Kjær MA, Todorcević M, Torstensen BE, Vegusdal A, Ruyter B. Dietary n-3 HUFA affects mitochondrial fatty acid beta-oxidation capacity and susceptibility to oxidative stress in Atlantic salmon. Lipids. 2008;43:813-27. https://doi.org/10.1007/s11745-008-3208-z.

16. Torstensen BE, Nanton DA, Olsvik PA, Sundvold H, Stubhaug I. Gene expression of fatty acid-binding proteins, fatty acid transport proteins ( $c d 36$ and FATP) and $\beta$-oxidation-related genes in Atlantic salmon (Salmo salar L.) fed fish oil or vegetable oil. Aquac Nutr. 2009;15:440-51. https://doi.org/10. 1111/j.1365-2095.2008.00609.x.

17. Alves Martins D, Rocha F, Martínez-Rodríguez G, Bell G, Morais S, Castanheira F, et al. Teleost fish larvae adapt to dietary arachidonic acid supply through modulation of the expression of lipid metabolism and stress response genes. Br J Nutr. 2012;108:864-74. https://doi.org/10.1017/S0007114511006143.

18. Figueiredo-Silva AC, Kaushik S, Terrier F, Schrama JW, Médale F, Geurden I. Link between lipid metabolism and voluntary food intake in rainbow trout fed coconut oil rich in medium-chain TAG. Br J Nutr. 2012;107:1714-25. https://doi.org/10.1017/S0007114511004739.

19. Zuo R, Ai Q, Mai K, Xu W. Effects of conjugated linoleic acid on growth, non-specific immunity, antioxidant capacity, lipid deposition and related gene expression in juvenile large yellow croaker (Larmichthys crocea) fed soyabean oil-based diets. Br J Nutr. 2013;110:1220-32. https://doi.org/10. 1017/S0007114513000378

20. Coccia E, Varricchio E, Vito P, Turchini GM, Francis DS, Paolucci M. Fatty acidspecific alterations in Leptin, PPARa, and CPT-1 gene expression in the rainbow trout. Lipids. 2014;49:1033-46. https://doi.org/10.1007/s11745-014-3939-y.

21. De Santis C, Taylor JF, Martinez-Rubio L, Boltana S, Tocher DR. Influence of development and dietary phospholipid content and composition on intestinal transcriptome of Atlantic salmon (Salmo salar). PLoS One. 2015;10: 1-16. https://doi.org/10.1371/journal.pone.0140964.

22. Fontagne S, Geurden I, Escaffre A, Bergot P. Histological changes induced by dietary phospholipids in intestine and liver of common carp (Cyprinus carpio L.) larvae. Aquaculture. 1998;161:213-23.

23. Geurden I, Bergot P, Schwarz L, Sorgeloos P. Relationship between dietary phospholipid classes and neutral lipid absorption in newly-weaned turbot, Scophthalmus maximus. Fish Physiol Biochem. 1998;19:217-28.

24. Salhi M, Hernández-Cruz $C$, Bessonart M, Izquierdo M, Fernández-Palacios $H$. Effect of different dietary polar lipid levels and different n-3 HUFA content in polar lipids on gut and liver histological structure of gilthead seabream (Sparus aurata) larvae. Aquaculture. 1999;179:253-63.

25. Hadas E, Koven W, Sklan D, Tandler A. The effect of dietary phosphatidylcholine on the assimilation and distribution of ingested free oleic acid (18:1 n-9) in gilthead seabream (Sparus aurata) larvae. Aquaculture. 2003;217:577-88.

26. Koven WM, Kolkovski S, Tandler A, Kissil GW, Sklan D. The effect of dietary lecithin and lipase, as a function of age, on n-9 fatty acid incorporation in the tissue lipids of Sparus aurata larvae. Fish Physiol Biochem. 1993;10:35764. https://doi.org/10.1007/BF00004502

27. Daprà F, Geurden I, Corraze G, Bazin D, Zambonino-Infante J-L, FontagnéDicharry S. Physiological and molecular responses to dietary phospholipids vary between fry and early juvenile stages of rainbow trout (Oncorhynchus mykiss). Aquaculture. 2011;319:377-84. https://doi.org/10.1016/j.aquaculture.2011.07.016.

28. Gibellini F, Smith TK. The Kennedy pathway--De novo synthesis of phosphatidylethanolamine and phosphatidylcholine. IUBMB Life. 2010;62: 414-28. https://doi.org/10.1002/iub.337.

29. Li Z, Vance DE. Phosphatidylcholine and choline homeostasis. J Lipid Res. 2008;49:1187-94. https://doi.org/10.1194/jlr. R700019-JLR200.

30. Ketola HG. Choline metabolism and nutritional requirement of lake trout (Salvelinus namaycush). J Anim Sci. 1976;43:474-7.

31. Rumsey GL. Choline-betaine requirements of rainbow trout (Oncorhynchus mykiss). Aquaculture. 1991;95:107-16. https://doi.org/10.1016/00448486(91)90077-K.

32. Duan $Y$, Zhu $X$, Han D, Yang $Y$, Xie S. Dietary choline requirement in slight methionine-deficient diet for juvenile gibel carp (Carassius auratus gibelio). Aquac Nutr. 2012;18:620-7. https://doi.org/10.1111/j.1365-2095.2011.00930.x.

33. Arai S, Nose T, Hashimoto Y. Qualitative requirements of young eels, Anguilla japonica, for water-soluble vitamins and their deficiency symptoms. Bull Freshw Res Lab. 1972;22:69-83.
34. Poston HA. Effect of body size on growth, survival, and chemical composition of Atlantic Salmon fed soy lecithin and choline. Progress FishCulturist. 1990:52:226-30. https://doi.org/10.1577/1548-8640(1990)052<0226: EOBSOG > 2.3.CO;2.

35. Griffin ME, Wilson KA, White MR, Brown PB. Dietary choline requirement of juvenile hybrid striped bass. J Nutr. 1994;124:1685-9 http://europepmc.org/ abstract/MED/8089736. Accessed 28 Nov 2014

36. Shiau S-Y, Lo P-S. Research communication dietary choline requirements of juvenile hybrid Tilapia, Oreochromis niloticus x O aureus. J Nutr. 2000;130:100-3.

37. Hung SSO, Berge GM, Storebakken T. Growth and digestibility effects of soya lecithin and choline chloride on juvenile Atlantic salmon. Aquac Nutr. 1997;3:141-4. https://doi.org/10.1046/j.1365-2095.1997.00080.x.

38. Wu P, Feng L, Kuang S-Y, Liu Y, Jiang J, Hu K, et al. Effect of dietary choline on growth, intestinal enzyme activities and relative expressions of target of rapamycin and elF4E-binding protein2 gene in muscle, hepatopancreas and intestine of juvenile Jian carp (Cyprinus carpio var. Jian). Aquaculture. 2011; 317:107-16. https://doi.org/10.1016/j.aquaculture.2011.03.042.

39. Niu J, Liu YJ, Tian LX, Mai KS, Yang HJ, Ye CX, et al. Effects of dietary phospholipid level in cobia (Rachycentron canadum) larvae: growth, survival, plasma lipids and enzymes of lipid metabolism. Fish Physiol Biochem. 2008; 34:9-17. https://doi.org/10.1007/s10695-007-9140-y.

40. Tocher DR, Bendiksen EA, Campbell PJ, Bell JG. The role of phospholipids in nutrition and metabolism of teleost fish. Aquaculture. 2008;280:21-34. https://doi.org/10.1016/j.aquaculture.2008.04.034.

41. Krahmer N, Guo Y, Wilfling F, Hilger M, Lingrell S, Heger K, et al. Phosphatidylcholine synthesis for lipid droplet expansion is mediated by localized activation of CTP:Phosphocholine cytidylyltransferase. Cell Metab. 2011;14:504-15. https://doi.org/10.1016/j.cmet.2011.07.013.

42. Olsen RE, Myklebust R, Kaino T, Ringø E. Lipid digestibility and ultrastructural changes in the enterocytes of Arctic char (Salvelinus alpinus $L$.) fed linseed oil and soybean lecithin. Fish Physiol Biochem. 1999;21:35-44.

43. Taylor JF, Martinez-Rubio L, del Pozo J, Walton JM, Tinch AE, Migaud H, et al. Influence of dietary phospholipid on early development and performance of Atlantic salmon (Salmo salar). Aquaculture. 2015:448:262-72. https://doi.org/10.1016/j.aquaculture.2015.06.012.

44. Li JY, Li XF, Xu WN, Zhang CN, Liu WB. Effects of dietary choline supplementation on growth performance, lipid deposition and intestinal enzyme activities of blunt snout bream Megalobrama amblycephal fed highlipid diet. Aquac Nutr. 2016;22:181-90.

45. Cornell RB, Ridgway ND. CTP:phosphocholine cytidylyltransferase: function, regulation, and structure of an amphitropic enzyme required for membrane biogenesis. Prog Lipid Res. 2015;59:147-71. https://doi.org/10.1016/j.plipres. 2015.07.001.

46. Jia L, Betters JL, Yu L. Niemann-pick C1-like 1 (NPC1L1) protein in intestinal and hepatic cholesterol transport. Annu Rev Physiol. 2011;73:239-59.

47. Brown M, Yu L. Opposing gatekeepers of apical sterol transport: Niemannpick C1-like (NPC1L1) and ATP-binding cassette transporters G5 and G8 (ABCG5/ABCG8). Immunol Endocr Metab Agents Med Chem. NIH Public Access. 2009:9:18-29.

48. Caballero MJ, Gallardo G, Robaina L, Montero D, Fernández A, Izquierdo M. Vegetable lipid sources in vitro biosyntheis of triacylglycerols and phospholipids in the intestine of sea bream (Sparus aurata). Br J Nutr. 2007; 95:448. https://doi.org/10.1079/BJN20051529.

49. Lagakos WS, Guan X, Ho S-Y, Sawicki LR, Corsico B, Kodukula S, et al. Liver fatty acid-binding protein binds monoacylglycerol in vitro and in mouse liver cytosol. J Biol Chem. 2013;288:19805-15. https://doi.org/10.1074/jbc. M113.473579.

50. Li K. Phospholipids in Atlantic cod (Gadus morhua L .) larvae rearing: Incorporation of DHA in live feed and larval phospholipids and the metabolic capabilities. Norwegian University Of Science and Technology; 2015.

51. Kamalam BS, Panserat S, Aguirre P, Geurden I, Fontagné-Dicharry S, Médale F. Selection for high muscle fat in rainbow trout induces potentially higher chylomicron synthesis and PUFA biosynthesis in the intestine. Comp Biochem Physiol A Mol Integr Physiol. 2013;164:417-27. https://doi.org/10. 1016/j.cbpa.2012.11.020.

52. Fontagne S, Burtaire L, Corraze G, Bergot P. Effects of dietary medium-chain triacylglycerols (tricaprylin and tricaproin) and phospholipid supply on survival, growth and lipid metabolism in common carp (Cyprinus carpio L .) larvae. Aquaculture. 2000:190:289-303.

53. da Silva RP, Kelly KB, Lewis ED, Leonard KA, Goruk S, Curtis JM, et al. Choline deficiency impairs intestinal lipid metabolism in the lactating rat. J Nutr Biochem. 2015;26:1077-83. https://doi.org/10.1016/j.jnutbio.2015.04.015. 
54. Lee B, Zhu J, Wolins NE, Cheng J-X, Buhman KK. Differential association of adipophilin and TIP47 proteins with cytoplasmic lipid droplets in mouse enterocytes during dietary fat absorption. Biochim Biophys Acta. 1791;2009: 1173-80. https://doi.org/10.1016/j.bbalip.2009.08.002.

55. Straub BK, Gyoengyoesi B, Koenig M, Hashani M, Pawella LM, Herpel E, et al. Adipophilin/perilipin-2 as a lipid droplet-specific marker for metabolically active cells and diseases associated with metabolic dysregulation. Histopathology. 2013;62:617-31. https://doi.org/10.1111/his.12038.

56. Li Y, Kortner TM, Chikwati EM, Munang'andu HM, Lock EJ, Krogdahl Å. Gut health and vaccination response in pre-smolt Atlantic salmon (Salmo salar) fed black soldier fly (Hermetia illucens) larvae meal. Fish Shellfish Immunol. 2019;86:1106-13. https://doi.org/10.1016/j.fsi.2018.12.057.

57. Craig SR, Gatlin DM. Growth and body composition of juvenile red drum (Sciaenops ocektus) fed diets containing lecithin and supplemental choline. Aquaculture. 1997;151:259-67.

58. Ogino C, Uki N, Watanabe T, lida Z, Ando K. B vitamin requirements of carp. 4. Requirement for choline. Bull Japanese Soc Sci Fish. 1970;36:1140-6 http://www. cabdirect.org/abstracts/19721406454.html. Accessed 25 Nov 2014.

59. Jiang GZ, Wang M, Liu WB, Li GF, Qian Y. Dietary choline requirement for juvenile blunt snout bream, Megalobrama amblycephala. Aquac Nutr. 2013; 19:499-505.

60. Li J, Zhang D, Xu W, Jiang G, Zhang C, Li X, et al. Effects of dietary choline supplementation on growth performance and hepatic lipid transport in blunt snout bream (Megalobrama amblycephala) fed high-fat diets. Aquaculture. 2014; 434:340-7. https://doi.org/10.1016/j.aquaculture.2014.08.006.

61. Fisher EA, Ginsberg HN. Complexity in the secretory pathway: the assembly and secretion of apolipoprotein B-containing lipoproteins. J Biol Chem. 2002;277:17377-80.

62. Fisher EA, Pan M, Chen $X$, Wu X, Wang $H$, Jamil $H$, et al. The triple threat to nascent apolipoprotein $B$ : evidence for multiple, distinct degradative pathways. J Biol Chem. 2001;276:27855-63.

63. Olofsson SO, Stillemark-Billton P, Asp L. Intracellular assembly of VLDL: two major steps in separate cell compartments. Trends Cardiovasc Med. 2000;10: 338-45.

64. Tocher DR, Glencross BD. Lipids and fatty acids. In: Dietary nutrients, additives, and fish health; 2015. p. 47-94.

65. D'Abramo LRD, Bordner CE, Conklin DE. Relationship between dietary Phosphatidylcholine and serum cholesterol in the lobster Homarus sp. Mar Biol. 1982;235:231-5.

66. Kortner TM, Björkhem I, Krasnov A, Timmerhaus G, Krogdahl A. Dietary cholesterol supplementation to a plant-based diet suppresses the complete pathway of cholesterol synthesis and induces bile acid production in Atlantic salmon (Salmo salar L.). Br J Nutr. 2014;111:2089-103. https://doi. org/10.1017/S0007114514000373.

67. Kortner TM, Penn MH, Björkhem I, Måsøval K, Krogdahl Å. Bile components and lecithin supplemented to plant based diets do not diminish diet related intestinal inflammation in Atlantic salmon. BMC Vet Res. 2016;12:112. https://doi.org/10.1186/s12917-016-0819-0.

68. Chimsung N, Lall SP, Tantikitti C, Verlhac-Trichet V, Milley JE. Effects of dietary cholesterol on astaxanthin transport in plasma of Atlantic salmon (Salmo salar). Comp Biochem Physiol B Biochem Mol Biol. 2013;165:73-81. https://doi.org/10.1016/j.cbpb.2013.02.007.

69. Fournier N, de la Llera MM, Burkey BF, Swaney JB, Paterniti J, Moatti N, et al. Role of HDL phospholipid in efflux of cell cholesterol to whole serum: studies with human apoA-I transgenic rats. J Lipid Res. 1996;37:1704-11 http://www.ncbi.nlm.nih.gov/pubmed/8864954.

70. Austreng E. Digestibility determination in fish using chromic oxide marking and analysis of contents from different segments of the gastrointestinal tract. Aquaculture. 1978;13:266-72.

71. Krasnov A, Timmerhaus G, Afanasyev S, Jørgensen SM. Development and assessment of oligonucleotide microarrays for Atlantic salmon (Salmo salar L.). Comp Biochem Physiol Part D Genomics Proteomics. 2011;6:31-8. https://doi.org/10.1016/j.cbd.2010.04.006.

72. Bustin SA, Benes V, Garson JA, Hellemans J, Huggett J, Kubista M, et al. The MIQE guidelines: minimum information for publication of quantitative realtime PCR experiments. Clin Chem. 2009;55:611-22. https://doi.org/10.1373/ clinchem.2008.112797.

73. Kortner TM, Valen EC, Kortner H, Marjara IS, Krogdahl A, Bakke AM Candidate reference genes for quantitative real-time PCR (qPCR) assays during development of a diet-related enteropathy in Atlantic salmon (Salmo salar L.) and the potential pitfalls of uncritical use of normalization software tools. Aquaculture. 2011;318:355-63. https://doi.org/10.1016/j.aquaculture. 2011.05.038.

74. Livak KJ, Schmittgen TD. Analysis of relative gene expression data using real-time quantitative PCR and the 2(-Delta Delta C(T)) method. Methods. 2001;25:402-8. https://doi.org/10.1006/meth.2001.1262.

75. Refstie S, Helland SJ, Storebakken T. Adaptation to soybean meal in diets for rainbow trout, Oncorhynchus mykiss. Aquaculture. 1997;153:263-72. https:// doi.org/10.1016/S0044-8486(97)00025-2.

76. Parini $P$, Johansson $L$, Bröijersén $A$, Angelin B, Rudling M. Lipoprotein profiles in plasma and interstitial fluid analyzed with an automated gelfiltration system. Eur J Clin Investig. 2006;36:98-104. https://doi.org/10.1111/ j.1365-2362.2006.01597.x.

77. Lund E, Sisfontes L, Reihner E, Bjorkhem I. Determination of serum levels of unesterified lathosterol by isotope dilution-mass spectrometry. Scand J Clin Lab Invest. 1989:49:165-71 http://informahealthcare.com/doi/abs/10.3109/ 00365518909105417. Accessed 27 Nov 2014.

78. Lövgren-Sandblom A, Heverin M, Larsson H, Lundström E, Wahren J, Diczfalusy U, et al. Novel LC-MS/MS method for assay of 7alpha-hydroxy-4cholesten-3-one in human plasma. Evidence for a significant extrahepatic metabolism. J Chromatogr B. 2007;856:15-9. https://doi.org/10.1016/j. jchromb.2007.05.019.

79. Dzeletovic S, Breuer O, Lund E, Diczfalusy U. Determination of cholesterol oxidation products in human plasma by isotop dilution-mass spectrometry. Anal Biochem. 1995;225:73-80.

80. Acimovic J, Lövgren-Sandblom A, Monostory K, Rozman D, Golicnik M, Lutjohann D, et al. Combined gas chromatographic/mass spectrometric analysis of cholesterol precursors and plant sterols in cultured cells. J Chromatogr B Analyt Technol Biomed Life Sci. 2009;877:2081-6. https://doi. org/10.1016/j.jchromb.2009.05.050.

81. Folch J, Lees M, Stanley S. A simple method for the isolation and purification of total lipids from animal tissues. J Biol Chem. 1957;226:497-507.

82. Austreng E, Storebakken T, Thomassen MS, Refstie S, Thomassen Y. Evaluation of selected trivalent metal oxides as inert markers used to estimate apparent digestibility in salmonids. Aquaculture. 2000;188:65-78. https://doi.org/10.1016/S0044-8486(00)00336-7.

\section{Publisher's Note}

Springer Nature remains neutral with regard to jurisdictional claims in published maps and institutional affiliations.

Ready to submit your research? Choose BMC and benefit from:

- fast, convenient online submission

- thorough peer review by experienced researchers in your field

- rapid publication on acceptance

- support for research data, including large and complex data types

- gold Open Access which fosters wider collaboration and increased citations

- maximum visibility for your research: over $100 \mathrm{M}$ website views per year

At BMC, research is always in progress.

Learn more biomedcentral.com/submissions 